Participatory Educational Research (PER)

Vol. 2(1), pp 57-65, April, 2015

Available online at http://www.partedres.com

ISSN: 2148-6123

http://dx.doi.org/10.17275/per.15.05.2.1

\title{
Examination of Auditory Reasoning and Processing Skills in terms of Gender, Type of School and Pre-school Education Period
}

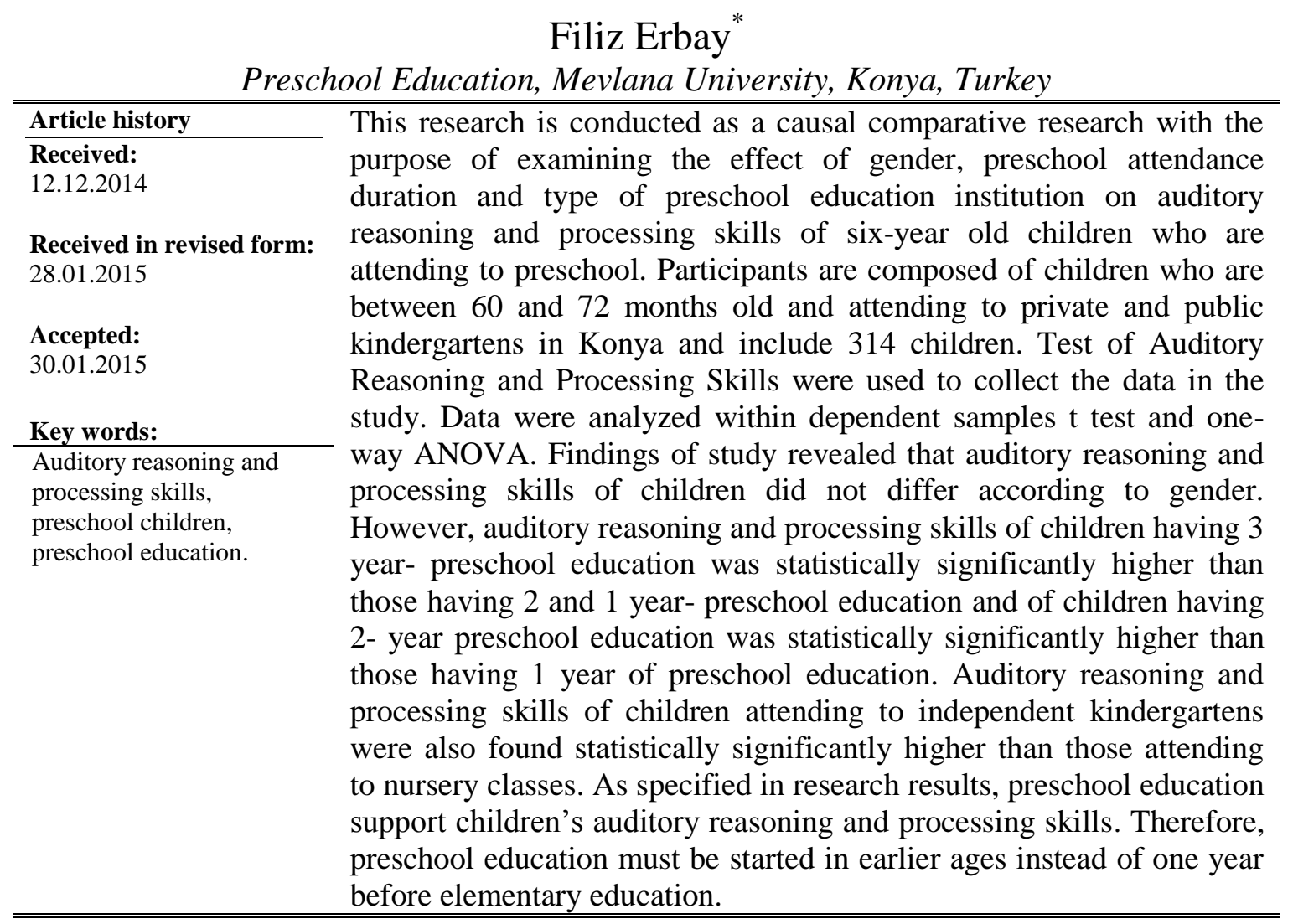

\section{Introduction}

Requirements of the current age make it necessary for individuals to recognize themselves and their surroundings well, to be able to analyze and interpret cause and effect relationships between events and situations they face, be a kind of persons that can offer their own solution to different problems. At the same time, there is a need in the society for the people that are willing to learn, not satisfied by the existing information, who explore, question, test the knowledge, make inference in order to reach level of social knowledge, in other words for the people with developed reasoning skills (Tepeli, 2011).

Auditory reasoning and processing skills are defined as children's auditory perceptions,

\footnotetext{
* Correspondence: ferbay@mevlana.edu.tr
} 
their ability to think about their perceptions, to make comments out of their perceptions within the frame of reason and results and find solutions to problems by diagnosing similarities and differences and organizing these relations (Gardner, 1993). All these skills enable children to solve problems easily by creating a reason-result relationship and discovering new solutions. Additionally, they reinforce creativity and provide children with the necessary knowledge and experience and they act as a guide to transfer their knowledge and experience to real life practices (Erbay, 2009).

Studies related to cognitive development and reasoning skills in literature examined elements influencing these skills and revealed that preschool education and also different educational programs were effective on these skills. Common results of these studies are that having preschool education supports different skills related to cognitive development in children (Çapri \& Çelikkaleli, 2005; Demir, 2010; Ekinci, 2001; Erbay, 2009; Kandır \& Orçan, 2009; Kidd et al. 2008; Kuday, 2007; İnal, 2010). Again in different studies related to reasoning skills in children, effects of gender variable was searched and different results were obtained. In some of these studies, it is included that there are differences in female and male children's reasoning skills in numerical, verbal and in more different fields (Strand et al., 2006; Adeyinka et al., 2008); while, in some of them, it is stated that there was no difference between the scores of reasoning skills of female and male children in different fields (Tian an Huang 2009; Tepeli, 2011; Lohman \& Laki, 2008; Wang, 2004, Caropreso \& White, 2001).

As it is seen, having preschool education positively affects cognitive and reasoning skills of children. There are more findings of study about this subject matter, and this subject was scientifically proved for many times. However, there are limited number of studies which reveals effect of starting preschool education in early ages and period of preschool education. These studies are not those especially focused on reasoning and processing skills. Therefore, in these studies, beyond having preschool education, effect of period of preschool education on auditory reasoning and processing skills are also wanted to be studied. Study differs both in respect of revealing the differences between these skills of children who started preschool education in early ages than those started in late ages, and in respect of studying auditory reasoning and processing skills which is a different reasoning skills. Finding to be obtained from this study is considered to reveal importance and meaning of starting preschool education in early ages.

In this study, it is required to study effect of type of educational institution of children on auditory reasoning and processing skills of children, because there might be difference in educational environment when the type of institution differs. In literature, it is stated that educational environment of children effects their perception, learning, cooperation behaviors, language, social -emotional, psychomotor developments and literacy skills (Read et al., 1999; Mushburn, 2008; Moore et al., 2003). In their study, Çapri and Çelikkaleli (2005) emphasize that period of education and, depending on that, classroom atmosphere effects cognitive development and that the period of education and stimulating environment offered to individual in the process of education are extremely important in respect of cognitive development. It is a subject studied for the 
first time in literature that whether or not auditory reasoning and processing skills of children taking education in different environments differ. Therefore, it is thought that results of study will fill the gap about this subject in literature and, from this aspect, they will contribute to literature.

From all these point of views, the purpose of this study examining the effect of gender, preschool attendance duration and type of preschool education institution on auditory reasoning and processing skills of six-year old children who are attending to preschool.

Answer of following questions were sought in the direction of this general purpose.

(1) Do mean scores of auditory reasoning and processing skills of children statistically significantly differ according to gender?

(2) Do mean scores of auditory reasoning and processing skills of children statistically significantly differ according to period of preschool education)

(3) Do mean scores of auditory reasoning and processing skills of children statistically significantly differ according to the type of preschool educational institution where they are attending?

\section{Method}

Dependent variable of this study is auditory reasoning and processing skills and independent variables of this study are gender, period of preschool education and type of preschool educational institution. In order to reveal effects of independent variables on dependent variable, a causal comparative research is conducted.

The participants of the study are ranging in month from 60-72 (Mean: 66.1, Sd: 4.2) children who are the students of both private and state pre-schools affiliated to Ministry of Education in central districts of Konya in Turkey. The kindergartens and nursery class included in the study were selected based on random sampling strategies namely by cluster sampling. The participants includes 314 children; 156 female children, 158 male children. 177 of participants consisted of children having 1 year preschool education, 91 of them consisted of children having 2 year preschool education and 46 of them of those having 3 year preschool education. Also 117 of children were attending nursery classes of elementary schools and 197 were attending independent kindergartens

Test of Auditory Reasoning and Processing Skills: (TARPS) was used as the data collection tool in the study. Test of Auditory Reasoning and Processing Skills (TARPS), which was developed by Gardner (1993), provides information about issues such as how children think, comprehend, generate ideas, draw inferences, solve problems obtain information, about how they list, comprehend, interpret and relate what they have perceived aurally. TARPS measures the quality and amount of a subject's auditory thinking and reasoning and children's skills to draw inferences and implement and use the ideas developed from what they have perceived auditory. The test assesses auditory reasoning and processing skills of children aged 5 to 14 . 
The adaptation of the test to Turkish for 60-72 month children was conducted by Erbay (2009). The test involves 31 open ended items. For example, following questions are involved in the scale: "In what kind of water does saltwater fish live?"; "What are the similar features of orange juice, water and milk?"; "Why do people attend university?" Test measures skills of general information, comprehension, similarities, analogical completion, finding reasons, arithmetical reasoning and verbal absurdities but as it is done in the original test, they are evaluated on a single dimension as auditory reasoning and processing skills. When scoring the test each correct answer is given 1 point and false answers and "do not know" answers are given 0 point. For all of the test minimum score is 0 and maximum score is 31 . Nine field experts were received for content validity of the test. Internal consistency coefficient, KR-20 value and the split half-test correlation value for Auditory Reasoning and Processing Skills Test were calculated to be 0.86, 0.87, and 0.83, respectively (Erbay, 2009).

First of all, required permission was obtained from Konya Province Ministry of National Education. Instruments were applied to all children in kindergartens which give permission for the research. In this study, 'Test of Auditory Reasoning and Processing Skills TARPS' was applied by the researcher. Researcher firstly introduced themselves to children with help of their teachers and by having conversation with children, children's concerns about the application were tried to be eliminated. In order to help children pay attention and concentrate on the test, test application was conducted in a separate quiet place; and in face to face manner while child and the researcher were sitting in child-sized chairs around a table. For TARPS, children were demanded to answer the open-ended questions asked by researcher. Scale was applied to children individually by researcher. Children's answers were recorded to scale answer form arranged for each child's responses. Application of test took about 15-20 minutes.

Dependent variable of this study is auditory reasoning and processing skills and independent variables of this study are gender, period of preschool education and type of preschool educational institution. Period of preschool education is discussed into three dimensions. Auditory reasoning and processing skills of children having 1 year, 2 year and 3 year preschool education were examined. Type of the preschool educational institution was discussed as nursery class and kindergarten. It was assessed with t test (independent sample t-Test) in independent scales whether or not scores of auditory reasoning and processing skills and type of the preschool educational institution differ, and with one-way ANOVA whether or not it differs according to the period of preschool education. In the analyses of data, SPSS 15 program was used.

\section{Results}

In this part, independent sample t-Test, one-way Anova analyses are given. Table 1 presents independent sample t-Test results of auditory reasoning and processing skills scores according to the gender. 
Table 1. T-Test results of auditory Reasoning and Processing Skills Scores according to the gender.

\begin{tabular}{lllllll}
\hline Gender & $\mathrm{N}$ & $\mathrm{X}$ & $\mathrm{S}$ & $\mathrm{df}$ & $\mathrm{t}$ & $\mathrm{p}$ \\
\hline Girl & 156 & 15,54 & 6,67 & 312 & 0,77 & 0,44 \\
Boy & 158 & 16,11 & 6,41 & & & \\
\hline
\end{tabular}

When Table 1 is examined, children's mean scores of auditory reasoning and processing skills did not differ according to the gender. There is not any statistically significant differentiation between mean scores of girls and boys ( $t=0,77, \mathrm{p}>0.01)$. Girls' mean scores of auditory reasoning and processing skills was 15,54 , while the mean scores of boys was 16,11 . This result shows that gender variable does no have any affect on auditory reasoning and processing skills.

Table 2 presents One-way ANOVA results of auditory reasoning and processing skills scores according pre-school education period.

Table 2. One-way ANOVA results of Auditory Reasoning and Processing Skills Scores according to pre-school education period.

\begin{tabular}{lcccccc}
\hline $\begin{array}{l}\text { Source of } \\
\text { Variance }\end{array}$ & Sum of squares & $\mathrm{df}$ & Mean Square & $\mathrm{f}$ & $\mathrm{p}$ & $\begin{array}{c}\text { Significant } \\
\text { different }\end{array}$ \\
$\begin{array}{l}\text { Between groups } \\
\text { Within Groups }\end{array}$ & 7345,818 & 2 & 3672,909 & 189,111 &, 000 & $1-2,2-3,1-3$ \\
Total & 13386,054 & 311 & 19,422 & & & \\
\hline
\end{tabular}

When Table 2 is examined, it is seen that there was a statistically significant difference between children's auditory reasoning and processing skills in terms of pre-school education period $\left(\mathrm{F}_{(2-311)}=189,111, \mathrm{p}<0,01\right)$. In other words, children's auditory reasoning and processing skills significantly differs according to the pre-school education. According to the LSD test results which was performed in order to learn differences between groups, auditory reasoning and processing skills of those having 3 years $(X=24,48)$ preschool education was found significantly higher than those having 2 years and one year preschool education; and scores of those having 2 years $(X=19,25)$ preschool education was found significantly higher than those having 1 year $(X=11,82)$ preschool education. Period of preschool education supports auditory reasoning and processing skills of children.

Table 3 presents independent sample t-Test results of auditory reasoning and processing skills scores according to the type of school.

Table 3. T-Test results of Auditory Reasoning and Processing Skills Scores according to the type of school

\begin{tabular}{lllllll}
\hline Type of school & $\mathrm{N}$ & $\mathrm{X}$ & $\mathrm{S}$ & $\mathrm{df}$ & $\mathrm{t}$ & $\mathrm{p}$ \\
\hline Nursery class & 197 & 12,91 & 5,78 & 312 & 12,60 & 0,000 \\
Independent & 117 & 20,75 & 4,47 & & & \\
kindergarten & & & & & & \\
\hline
\end{tabular}

As given in Table 3, children's mean scores of auditory reasoning and processing skills significantly differ according to the type of school $(\mathrm{t}=12,60 \mathrm{p}<0.01)$. Mean scores of 
children attending an independent kindergarten is 20,75 and mean scores of children attending a nursery class is 12,91. Mean scores of children attending an independent kindergarten for auditory reasoning and processing skills were found significantly higher than the mean scores of children attending a nursery class.

\section{Discussion and Suggestions}

This study was made in order to compare auditory reasoning and processing skills of 6 year of female and male children who attend to nursery class and independent kindergartens and who received 1,2 and 3- year preschool education. Findings of study showed that these skills did not differ in children according to gender. In different studies, gender is discussed as a determining variable of cognitive skills and different results were reached. When results of these studies in literature are considered, it is seen that results supporting the results of this study took place.

Tepeli (2011), in her study, stated that gender was a significant predictor of children's auditory reasoning and processing skills, but it was not a significant predictor in the sub-dimensions of general information, arithmetic reasoning, analogical completion, causal reasoning and analogies. Lohman and Laki (2008) and Wang (2004) emphasized that there was not a significant difference between verbal, numerical and non-verbal reasoning skills of gifted children and normal development children and their gender. Caropreso and White (2001), in their research, specified that analogical reasoning skills of four, five and six year-old children with gifted children were not affected by gender variable. Tian and Huang (2009) stated that there was no statistically significant difference between spatial and numerical reasoning skills of female and male children.

Another result include in the findings of this study is that scores of Auditory Reasoning and Processing Skills of children having longer period of preschool education were higher than those having shorter period of preschool education. This is an expected result, because there is also support of cognitive development of children such as their social, emotional-psychomotor development among the purpose of preschool education (Biber, 2010; Güven and Efe Azkeskin, 2010). As children start this education in early ages, so their cognitive development and skills will support and develop. Theory of Vygotsky defines development as a social process and advocates that cognitive development realizes as a result of interaction of children with adults and more skilled peers. According to Vygotsky, beyond their abilities, by joining in several activities together, children first develop and practice cognitive skills which fall into their field of development (Erdiller, 2010). As Vygotsky stated in his theory, preschool education give children an opportunity to interact with their peers and also to go around with specialists and pedagogue adults out of their families and inner circles. For these reasons, auditory reasoning and processing skills that is a cognitive skill of children is supported and developed during the preschool education.

In a similar study, Kandır and Orçan (2009) determined that if age to start preschool 
education by children of families in low and high socio-economic status who attend nursery class decreases, Total Score of Early Learning Abilities (TSELA), subtotal scores of Thinking, Language and Number Skills increase. In his study, Demir (2010) revealed that preschool education and 2006 Preschool Education Program positively effect cognitive developments of both 36-48 months old and 49-60 months old children.

Lipman (1988) stated that it is not easy and rapid process to develop reasoning skills and emphasized that education programs must be used to develop reasoning skills (Akt. Criner, 1992). There are researches in literature which state that education programs develop reasoning skills of children.

Kidd et. al., (2008) stated that mathematic education program develops reasoning skills of children. Erbay (2009) indicated that drama education supports auditory reasoning and process skills of children, while Inal (2010) emphasized that the education she provided developed verbal, numeric and non-verbal reasoning abilities of children. All these results have the quality to support the result of findings.

Another result emerged in the light of the findings of study is that the mean average of auditory reasoning and processing skills of children attending kindergarten were significantly higher than mean average of those attending nursery class. Nursery classes are institutions which are within the structure of elementary school and generally included in the same building with elementary school classes and which usually consist of only one class. And independent kindergartens are only designed for the process of preschool education and it can be said that they are better than nursery classes in respect of indoor and outdoor, and in respect of physical equipment. Studies revealed that intelligence of children attending a good quality preschool educational institution were high (Demiriz, Kardağ, Ulutaş, 2003). Findings obtained from this study have parallels with this result.

Also another reason that will affect results in this manner is, as discussed in previous result, is considered to be related to period of school attendance. Most of the children who are sample and attend nursery classes receive the preschool education for the first time. Especially children attending nursery classes of state schools began preschool education at 6 year-old. And most of the children attending independent kindergartens are those attending preschool education at least for two years. As given in abovementioned finding, if the children begin preschool education at earlier ages, their auditory reasoning and process skills will be so higher. High mean scores of children attending an independent kindergarten can be explained with these reasons.

As specified in research results, preschool education support children's auditory reasoning and processing skills. The longer the children took this education, the higher their auditory reasoning and processing skills. Therefore, preschool education period of children must be extended. Preschool education must be started in earlier ages instead of one year before elementary education. Thus, preschool education must be made mandatory for earlier ages by the Ministry of National Education. Parents must be explained that they should their children to preschool education at earlier ages, and the 
importance of preschool education through seminars, books, newspapers, TV programs etc.

Different studies can be planned to test effects of preschool education on reasoning skills of children. In these studies, auditory reasoning and processing skills of children having or not having preschool education can be compared.

\section{Acknowledgement}

This paper was presented in The International Journal of Arts \& Sciences in Prag 2012.

\section{References}

Adeyinka,T., Adedeji, T., Adika, L.O., Toyoba, M.O. (2008). Relationship among demographic variables and pupil's reasoning ability. Electronic Journal of Research in Educational Psychology 6 (3) 709- 728.

Biber, K. (2010). Okul öncesi eğitimin tanımı, kapsamı, önemi ve temel ilkeleri. In S. Tümkaya \& F. Gülaçtı (Eds.), Early Childhood Education (pp 21-70). Ankara: Nobel Publising.

Caropreso, E. J., White, S. C. (2001). Analogical reasoning and giftedness: a comparison between identified gifted and nonidentified gifted. The Journal of Educational Research 87 (5) 271-278.

Criner, L. E. (1992). Teaching thinking and reasoning: a study of critical thinking in adults. Unpublished PhD Thesis. University of Arkansas. USA.

Çapri, B., Çelikkaleli, Ö. (2005). An investigation of first grade of elementary school childrens' (7-11-years-old) conservation development levels according to sex and grade. Mersin University, Journal of the Faculty of Education 1 (1) 48-65.

Demir, S. (2010). Comparison of 36-60 months children who are in pre-school according to their cognitive development qualities (Kütahya City case). (Unpublished Master's Thesis). University of Marmara, İstanbul.

Ekinci, O. (2001). The impact of preschooling on the success of first year elemantary school students (A case study in Gaziantep). (Unpublished Master's Thesis). University of Gaziantep, Gaziantep.

Erbay, F. (2009). The investigation of effects of creative drama education on six year old kindergarten students auditory reasoning and processing skills. (Unpublished PhD Thesis). Selçuk University, Konya

Erdiller, Z. B. (2010). Erken çocukluk eğitiminde temel kuram ve yaklaşımlar. In H. İ. Diken (Eds.), Early Childhood Education. (56-92). Ankara: Pegem Akademi Publishing.

Güven, G. \& Efe Azkeskin, K. (2010). Erken çocukluk eğitimi ve okul öncesi eğitim. In H. İ. Diken (Eds.), Early Childhood Education (2-53). Ankara: Pegem Akademi Publishing.

Inal, G. (2010). Determining the validity and reliability of cognitive abilities test form-6 and investigation of the effect of reasoning education program on six year old children's cognitive abilities (Unpublished $\mathrm{PhD}$ Thesis). Gazi University, Ankara. 
Kandır, A. \& Orçan, M. (2009). The study of pre-learning abilities of the children in five-six years of the families with lower and upper socio-economical levels. Afyon Kocatepe University Journal of Theoretical Science Education, 2 (1) 113.

Kidd, J. K., Pasnak, R., Gadzichowski, M., Ferral-Like, M., Gallington, D. (2008). Enhancing early numeracy by promoting the abstract thought involved in the oddity princible, seriation and conversation. Journal of Advanced Academics, 19 (2) 164-200.

Kuday, F. S. (2007). Comparison of cognitive development of children from ages 3 to 6 and who have taken family supported pre-school education, organization based pre-school education and who have not taken pre-school Education (Unpublished Master's Thesis). University of Marmara, İstanbul.

Kuru Turaşl1, N. (2010). The definitions, scope and importance of preschool education. In G. Haktanır (ed.), Introduction to Pre-School Education (pp.1-37) Ankara: Anı Publising.

Lohman, D. F., Lakin, J. (2008). Consistencies in sex differences on the cognitive abilities test across countries, grades, and cohorts. British Journal of Educational Psychology, 79 (2) 389-407.

Moore, G. T., Sugiyama, T., O’Donnell, L. (2003). Children's physical environment rating scale. Australian Early Childhood Association. p.73. Canberra

Mushburn, A. J. (2008). Quality of social and physical environments in preschools and children's development of academic, language and literacy skills. Applied Developmental Science 12 (3) 113-127.

Read, M. A., Sugawara, A. I., Brant, J. A. (1999). Impact of space and color in the psysical environment on preschool children's cooperative behavior. Environment And Behavior 31 (3) 413-428.

Strand, S., Deary, I.J. \& Smith, P. (2006). Sex differences in cognitive abilities test scores: a uk national picture. British Journal of Educational Psychology 76, 463- 480 .

Tepeli, K. (2011). Predictors of auditory reasoning and processing skills in preschool children. International Journal of Art And Science. Oral Presentation. Rome.

Tian, Z., Huang, X. (2009). A study of children's spatial reasoning and quantitative reasoning abilities. Journals of Mathematic Education. 2 (2), 80-93.

Wang, W. L. (2004). Gender differences in gifted children's spatial, verbal, and quantitative reasoning abilities in Taiwan. Available at: http://www.eric.ed.gov/PDFS/ED490622.pdf (Jun,11,2012) 